Abstracta Iranica Abstracta Iranica

Revue bibliographique pour le domaine irano-aryen

Volume 27 | 2006

Comptes rendus des publications de 2004

\title{
Mahindokht. La vie d'une Iranienne au vingtième siècle. L'Harmattan, Paris, 2004, 215 p.
}

\section{Anne-Sophie Vivier-Muresan}

\section{(2) OpenEdition}

1 Journals

Édition électronique

URL : http://journals.openedition.org/abstractairanica/6699

DOI : 10.4000/abstractairanica.6699

ISSN : 1961-960X

\section{Éditeur :}

CNRS (UMR 7528 Mondes iraniens et indiens), Éditions de l'IFRI

\section{Édition imprimée}

Date de publication : 15 mai 2006

ISSN : 0240-8910

\section{Référence électronique}

Anne-Sophie Vivier-Muresan, « Mahindokht. La vie d'une Iranienne au vingtième siècle. L'Harmattan, Paris, 2004, 215 p. », Abstracta Iranica [En ligne], Volume 27 | 2006, document 380, mis en ligne le 02 janvier 2007, consulté le 25 septembre 2020. URL : http://journals.openedition.org/abstractairanica/ 6699 ; DOI : https://doi.org/10.4000/abstractairanica.6699

Ce document a été généré automatiquement le 25 septembre 2020.

Tous droits réservés 


\title{
Mahindokht. La vie d'une Iranienne au vingtième siècle. L'Harmattan, Paris, 2004, 215 p.
}

\author{
Anne-Sophie Vivier-Muresan
}

1 Comme l'indique le titre, il s'agit là essentiellement d'une autobiographie - pour ne pas dire une auto-apologie. L'A., dans ce qui se voudrait une «leçon de vie », entreprend de faire défiler devant nos yeux la somme innombrable de catastrophes qui n'ont cessé de la poursuivre depuis sa naissance, afin de mieux prouver son incroyable capacité de lutte et de résistance. De ses malheurs d'enfant battue puis de jeune fille livrée au mariage forcé, à son exil post-révolutionnaire aux Etats-Unis et en France, en passant par ses déboires avec son époux et ses tracas pour construire la «villa de ses rêves » à quelques mètres du palais du Shâh, tout y passe, épuisant la compassion du lecteur. Cette tranche de vie aurait cependant pu être l'occasion de livrer un tableau de l'Iran des années quarante à nos jours, mais hélas, le lecteur reste là sur sa faim. L'A. est tellement préoccupée de nous peindre ses malheurs que le cadre socio-historique semble en carton-pâte. Tout juste trouve-t-elle bon de nous livrer quelques explications contextuelles, mais qu'elle condense alors sur un paragraphe : les rites de deuil dans le chiisme, la fête de Nowrouz, l'éducation morale - absurde selon ses propres termes des jeunes filles, et les causes de la Révolution iranienne sont ainsi exposés en quelques lignes à l'occasion d'anecdotes personnelles. Voici donc, en conclusion, un tableau bien superficiel, pour ne pas dire désolant, de la culture iranienne - plus ou moins assimilée ici aux mœurs de la haute société, où les ethnologues et sociologues auraient bien du mal à trouver de quoi se mettre sous la dent, si ce n'est en y voyant illustrés quelques principes bien connus: du partage des eaux dans un quartier de Téhéran au rôle important de la famille étendue dans l'éducation des enfants, en passant par l'utilisation de l'opium contre les rages de dent, la récolte est somme toute maigre. 
INDEX

Thèmes : 16.1. Iran

\section{AUTEURS}

ANNE-SOPHIE VIVIER-MURESAN

Paris 